\title{
A Cost-Effective Resonant Switched-Capacitor DC-DC Boost Converter - Experimental Results and Feasibility Model
}

Research Article

\author{
Zbigniew Waradzyn, Robert Stala, Aleksander Skała, Andrzej Mondzik, Adam Penczek
}

AGH University of Science and

Technology, Krakow, Poland

Received March 16, 2018; Accepted April 25, 2018

Abstract: This paper presents the results of experimental research of a resonant switched capacitor voltage multiplier in a cost-effective topology (CESCVM) with a limited number of active switches. In the charging mode of the switched capacitors, the converter utilizes only one active switch and a required number of diodes. Therefore, the cost of the converter is decreased as compared with that of a classical SCVM converter, owing to a lower number of switches and gate driver circuits, as well as a smaller PCB area. Moreover, the CESCVM has simpler control circuits and higher reliability. This paper presents the original experimental results of the operation of the CESCVM converter. A concept of the bootstrap supply of gate drivers of the flying switches is also examined.

Keywords: $D C$-DC converter $\bullet$ switched-capacitors $\bullet$ voltage multiplier $\bullet$ charge pump $\bullet$ ZCS

\section{Introduction}

Switched-capacitor converters have some important advantages in comparison to other concepts, such as high voltage gain, quasi inductiveless design, low weight, high efficiency and very simple control. Switched-capacitor (SC) DC-DC converters represent a wide family of topologies, with multiple representation in the scientific literature (Alam and Khan, 2014; Ben-Yaakov, 2012; Cao and Peng, 2010; Cervera et al., 2015; Cheung et al., 2013; Evzelman and Ben-Yaakov, 2013; loinovici, 2001; Kawa and Stala, 2016; Kawa et al., 2016; Lei and Pilawa-Podgurski, 2015; Mak et al., 1995; Mondzik et al., 2016; Waradzyn et al., 2017a,b) or can be used as a part of complex converters (Ye et al., 2014; Zajac et al., 2017).

a)

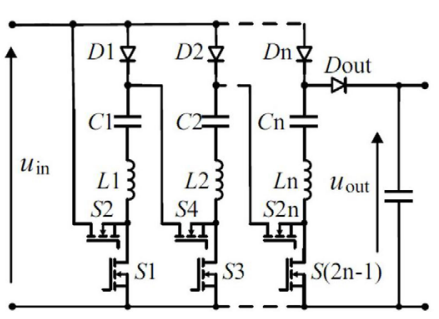

b)

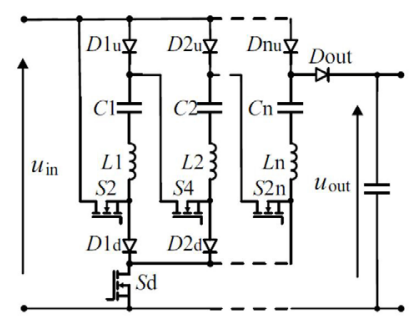

Fig. 1. DC-DC converter in the topology of: (a) basic Resonant Switched-Capacitor Voltage Multiplier (SCVM), (b) Cost-Effective Resonant SwitchedCapacitor Voltage Multiplier (CESCVM)(Waradzyn et al., 2017a) 
As typical switch-mode DC-DC boost converters can achieve very high efficiencies and regulation capabilities, the SCbased converters, such as SC multipliers (Kawa et al., 2016; Mondzik et al., 2016; Waradzyn et al., 2017a,b), can be an alternative option for the reason of high voltage gain capability and quasi-inductiveless design. The voltage gain of the SC converters can be achieved by multiplication of the source voltage and can depend on the number of SC cells. The SC-based topologies are also proposed as high voltage pulse generators (Alijani et al., 2016; Redondo, 2010; Sakamoto et al., 2012). Inductiveless design is a significant benefit in the converters where the volume and weight reduction is required, and in systems operating at high temperature (not applicable for ferrite-core chokes).

The basic switched-capacitor voltage multiplier (SCVM) (Fig. 1a) is an interesting and attractive topology from the standpoint of applications, owing to its relatively simple and modular composition. This converter can create a representative research model for the investigations of problems related to SC topologies. High efficiency of the power SC converter is achieved by the application of resonant circuits for charging and discharging of the switched capacitors. However, it contains a large number of active switches, especially in the case of high-voltage-gain units.

Therefore, a concept of cost reduction by using topologies with a lower number of transistors, such as the Cost-Effective SCVM (CESCVM) shown in Figure 1b (Waradzyn et al., 2017a), should be analysed. The topology is well-established, but to find its advantages and disadvantages, the experimental results of a particular design are interesting. This paper presents the results of the analytical and experimental research of the CESCVM, demonstrating the operation and feasibility of the converter. A simplification of the power circuit of an SCVM is demonstrated where some transistors are replaced by diodes. A very simple operation of the gate driver circuits is presented as well, where the bootstrap concept is introduced for all the high-side switches. The CESCVM efficiency is also precisely measured in the experimental setup, to verify the expected problems with power losses.

\section{Basic operation of the converters}

The SCVM (Fig. 1a) consists of $n$ cells, each with a switched capacitor, an inductor and semiconductor devices responsible for charging and discharging of the capacitor. In its basic switching strategy [two-stage (TS) switching], the converter operates in two cycles within each switching period $T_{\mathrm{S}}$ (Fig. 2): STAGE I (time interval $T_{\mathrm{SI}}$ ), when the switched capacitors are being charged from the input source with the switches $S_{1}, S_{3}, \ldots, S_{(2 n-1)}$ turned on, and STAGE II (time interval $T_{\mathrm{SII}}$ ), when the switched capacitors are being discharged to the output capacitor with the switches $S_{2}, S_{4}, \ldots, S_{2 n}$ turned on. Owing to the resonant character of the circuit, the current oscillates, and the converter can operate in the ZCS mode.

If the converter is not overloaded, the voltage ratio of the idealized converter depends only on the number of switching cells (Kawa et al., 2016; Waradzyn et al., 2017a,b)

$$
U_{\text {out }}=(n+1) U_{\text {in }} \text {. }
$$

The basic SCVM can be modified by replacing the transistors $S 1, S 3, \ldots, S_{(2 n-1)}$ with a single transistor $S_{\mathrm{d}}$ and diodes $D 1_{\mathrm{d}}, D 2_{\mathrm{d}}, \ldots, D_{(n-1) \mathrm{d}}($ Fig. 1b). Owing to this, there is a cost reduction - instead of $n$ transistors with their gate driver circuits, only one transistor and $n-1$ additional diodes are used. This converter (CESCVM - Cost-Effective Voltage Multiplier) operates in a similar way as the SCVM (Fig. 2).

\section{Current and voltage stresses}

Comparison of the SCVM and CESCVM (Fig. 1) shows that the current flowing through transistor $S_{d}$ in the CESCVM is $n$-fold than that flowing through transistors $S_{1}, S_{3}, \ldots, S_{(2 n-1)}$ in the SCVM. The currents in the diodes $D_{1 \mathrm{~d}}, D_{2 \mathrm{~d}}, \ldots, D_{(n-1) \mathrm{d}}$ equal those in transistors $S_{1}, S_{3}, \ldots, S_{(2 n-1)}$ in the SCVM. The current stresses of the other power-electronic devices remain the same as in the SCVM.

The voltage stresses on the transistors in the basic SCVM are dealt with in detail by Waradzyn et al. (2017b). In the CESCVM, the voltage across the transistor $S_{\mathrm{d}}$ is the same as that on $\mathrm{S}_{(2 n-1)}$ (low-side transistor nearest the output) in the SCVM, and equal to $n U_{\text {in }}$. In addition, the sum of the voltages across $S_{\mathrm{d}}$ and $D_{\text {Id }}$ in the SESCVM must equal the voltage on $S_{1}$ in the SCVM. Hence, the voltage stresses are: $U_{\text {in }}$ for $S_{1}$ (Waradzyn et al., 2017b) and $-(n-1) U_{\text {in }}$ for $D_{1 \mathrm{~d}}$. In a similar way, from $2 U_{\text {in }}$ on $S_{2}$ (Waradzyn et al., 2017b), we obtain - $(n-2) U_{\text {in }}$ on $D_{2 \mathrm{~d}}$, and so on. Therefore, as far as the low-side diodes in the CESCVM are concerned, the devices placed closer to the input side 
are exposed to higher voltage stresses than the more distant ones. This is contrary to the voltage stresses of $S_{1}, S_{3}, \ldots$ in the basic SCVM, in which the low-side devices closer to the input experience lower voltages.

The voltage stresses of the power-electronic devices in the CESCVM for $n=3$ are presented in Table 1. The voltages across transistors $S_{2}, S_{4}, \ldots$ equal $U_{\text {in }}$ during charging the switched capacitors and can be in the range of $U_{\text {in }} \div 2 U_{\text {in }}$ during the time intervals with zero input current.

a)

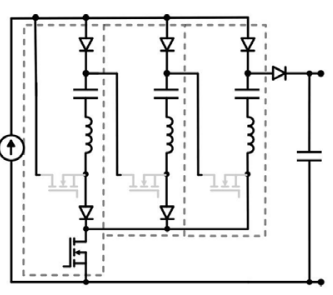

b)

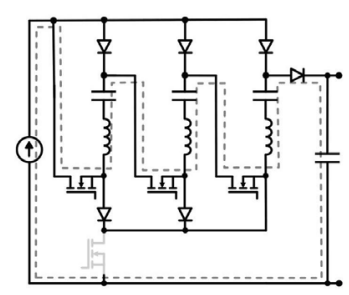

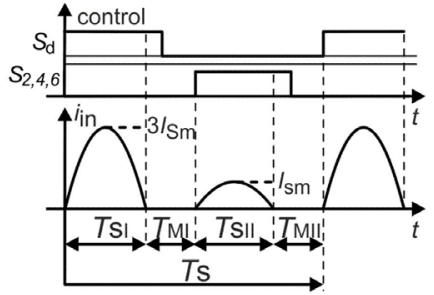

Fig. 2. Operation of CESCVM at $n=3$ : (a) charging and (b) discharging stages, (c) gate control signals and input current waveforms with definition of pulse durations and dead-times for both converters in Figure 1. $I_{\mathrm{sm}}$ - amplitude of current charging the output capacitor

Table 1. Voltage stresses of power-electronic devices in CESCVM (Fig. 1b) for $n=3$

\begin{tabular}{|c|c|c|c|c|c|}
\hline Device & $D_{1 \mathrm{u}}, \boldsymbol{D}_{2 \mathrm{~d}}$ & $D_{2 \mathrm{u}}, \boldsymbol{D}_{1 \mathrm{~d}}$ & $D_{3 \mathrm{u}}, D_{\text {out }}$ & $S_{2}, S_{4}, S_{6}$ & $S_{\mathrm{d}}$ \\
\hline Voltage stress & $-U_{\text {in }}$ & $-2 U_{\text {in }}$ & $-3 U_{\mathrm{in}}$ & $U_{\text {in }}$ to $2 U_{\text {in }}$ & $3 U_{\text {in }}$ \\
\hline
\end{tabular}

\section{Efficiency of the converters}

The efficiency of both converters was analysed in detail by Waradzyn et al. (2017a). According to this reference, the efficiency of the SCVM is as follows:

$$
\eta=1-\frac{\pi^{2} n}{4(n+1)^{2}} \frac{P_{\text {in }} r_{\mathrm{S}}}{U_{\text {in }}^{2}} \cdot \frac{T_{\mathrm{S}}}{T_{\mathrm{SI}}}-\frac{\Delta U_{D \mathrm{~S}}}{U_{\text {in }}}-\frac{\Delta W_{\mathrm{sw}} f_{S}}{P_{\text {in }}}
$$

where $n$ is the number of cells, $U_{\text {in }}$ is the input voltage, $P_{\text {in }}$ is the input power, $f_{\mathrm{s}}=1 / T_{\mathrm{s}}$ is the switching frequency, $T_{\mathrm{SI}}=T_{\mathrm{SII}}$ (Fig. 2) is the current pulse duration, $r_{\mathrm{s}}$ is the total resistance of each cell, including MOSFETs resistances, $\Delta U_{D \mathrm{~S}}$ is the voltage drop across each diode, $\Delta W_{\mathrm{sw}}$ is the energy lost at turn-on in all the MOSFET's resistances in a single switching cycle $T_{\mathrm{s}}$. It is also assumed that the values of the elements in each cell are the same, both in the circuits of charging and discharging of the cell capacitors, dead-times $T_{\mathrm{MI}}$ and $T_{\mathrm{MII}}$ (Fig. 2) are the same, and the voltage drops across the diodes remain constant in the conducting state.

In the CESCVM, it is assumed that the resistance of each circuit of charging the cell capacitor, excluding the branch with transistor $S_{\mathrm{d}}$, is $r_{\mathrm{S}}$, the resistance of the branch with transistor $S_{\mathrm{d}}$ is $r^{\prime \prime}$, the total resistance of each cell in the circuit of discharging the cell $k$ capacitor is $r_{\mathrm{S}}$ including the resistance of the MOSFET, and $\Delta U_{D S}$ is the voltage drop across each diode. Other assumptions are that $\Delta W_{\mathrm{sw}}{ }^{\prime}$ is the energy lost at turn-on in all the MOSFET's resistances in a single switching cycle $T_{\mathrm{S}}$ and the mean and rms values of the currents are the same as in the basic SCVM.

The efficiency of the CESCVM is the following (Waradzyn et al., 2017a):

$$
\eta=1-\frac{n}{n+1}\left[\frac{\pi^{2}}{8(n+1)} \frac{P_{\mathrm{in}}\left(r_{\mathrm{S}}^{\prime}+n r_{\mathrm{S}}^{\prime \prime}+r_{\mathrm{S}}\right)}{U_{\text {in }}^{2}} \cdot \frac{T_{\mathrm{S}}}{T_{\mathrm{SI}}}+2 \frac{\Delta U_{D \mathrm{~S}}}{U_{\text {in }}}\right]-\frac{\Delta W_{\mathrm{sw}}^{\prime} f_{S}}{P_{\mathrm{in}}}
$$

The modification of the topology affects the efficiency in two ways. Firstly, instead of conduction power losses in $S_{1}, S_{3}, \ldots, S_{(2 n-1)}$ in the SCVM, there are conduction power losses in transistor $S_{\mathrm{d}}$ and diodes $D_{k \mathrm{~d}}$ in the CESCVM. In most cases, the losses in the CESCVM are higher, owing to a higher current through transistor $S_{\mathrm{d}}$ (in regard to that flowing in $S_{1}, S_{3}, \ldots$ ) and losses in diodes $D_{k \mathrm{~d}^{-}}$. Therefore, a transistor with low $r_{\mathrm{DS}(\mathrm{on})}$ and diodes of low $V_{\mathrm{F}}$ are required in the CESCVM to minimize these losses. Secondly, switching losses are less in the CESCVM, due to a lower number of transistors. Hence, significant benefits of the application of the cost-effective multipliers are supposed in the systems where switching losses in the transistors represent an important part of total losses (low-power highfrequency systems). 
The ratio $T_{\mathrm{S}} / T_{\mathrm{SI}}$ can be replaced by $2 f_{0} / f_{\mathrm{s}}$ in (2) and (3), where $f_{0}$ is the resonant frequency of the series $L C$ circuit (Table 2) in each switching cell.

Figures 3 and 4 show the ratio of efficiencies of CESCVM to SCVM as a function of switching frequency $f_{\mathrm{s}}$ and power $P_{\text {in }}$, respectively. The parameters of both converters were assumed to be the same, where possible, and correspond to those of the experimental setup presented in Figure 5.

In most cases, the efficiency of the CESCVM is lower than that of the SCVM. The ratio of the efficiencies decreases with decreasing switching frequency $f_{\mathrm{s}}$ and increasing converter power.

The CESCVM can have a similar or even slightly higher efficiency only in the case of operation at low power and high frequency, when the switching losses are significant when compared to the conduction losses.

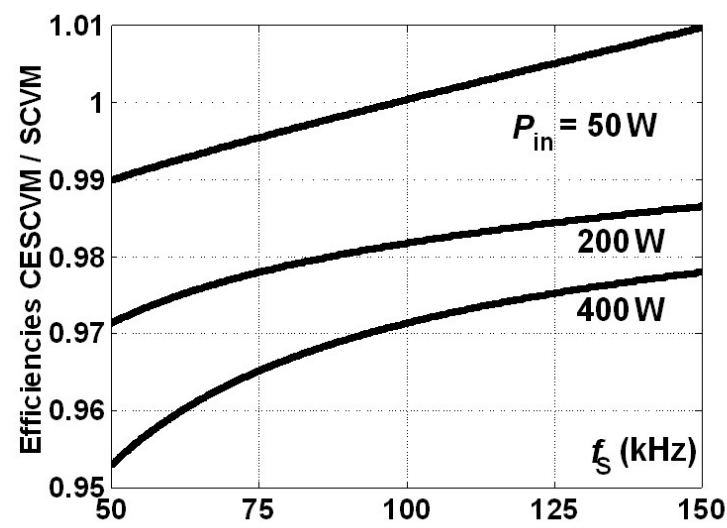

Fig. 3. Ratio of efficiencies of CESCVM to SCVM as a function of $f_{\mathrm{S}}$ for three values of $P_{\mathrm{in}}: 50 \mathrm{~W}, 200 \mathrm{~W}$ and $400 \mathrm{~W}$. Common parameters: $n=3$, $U_{\mathrm{in}}=40 \mathrm{~V}, r_{\mathrm{s}}=100 \mathrm{~m} \Omega, \Delta U_{\mathrm{DS}}=1.1 \mathrm{~V}$. SCVM: $\Delta W_{\mathrm{sw}}=16 \mathrm{~mJ}$. CESCVM: $r^{\prime}{ }_{\mathrm{S}}=70 \mathrm{~m} \Omega, r{ }_{\mathrm{s}}=50 \mathrm{~m} \Omega, \Delta W_{\mathrm{sw}}{ }^{\prime}=8 \mathrm{~mJ}$. Calculations based on (2) and (3)

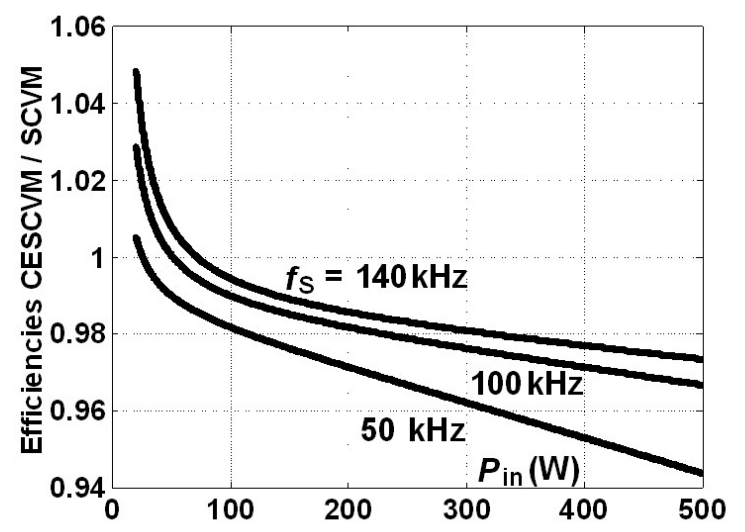

Fig. 4. Ratio of efficiencies of CESCVM to SCVM as a function of $P_{\text {in }}$ for three values of $f_{\mathrm{S}}: 50 \mathrm{kHz}, 100 \mathrm{kHz}$ and $140 \mathrm{kHz}$. Other parameters as those in Figure 3. Calculations based on (2) and (3)

\section{Experimental setup}

The experimental tests of the CESCVM were performed on a 3-cell setup with parameters presented in Table 2. The converter was designed using a 4-layer PCB layout with air-based inductances created on the tracks.

The switching frequency of ca. $136 \mathrm{kHz}$ was chosen for the setup operation. It is high enough to properly limit the values and size of the capacitors and inductances, and reasonable with regard to the switching losses and the gate circuit driver performance (Waradzyn et al., 2017a). The achieved inductance of ca. $0.85 \mu \mathrm{H}$ and the selected capacitance of $1.470 \mu \mathrm{F}$ in a series connection with the inductance give resonant frequency $f_{0}$ of $142.38 \mathrm{kHz}$.

Zero-current switching is only possible if the switching frequency is equal to or less than the resonant frequency. Therefore, the ZCS operation is possible at the assumed switching frequency. Moreover, the operation near 
resonance results in a low value of dead-times, which guarantees high efficiency (Waradzyn et al., 2017a) (the time intervals $T_{\mathrm{MI}}$ and $T_{\mathrm{MII}}$ are relatively short in comparison to the current pulses duration - Fig. 7).

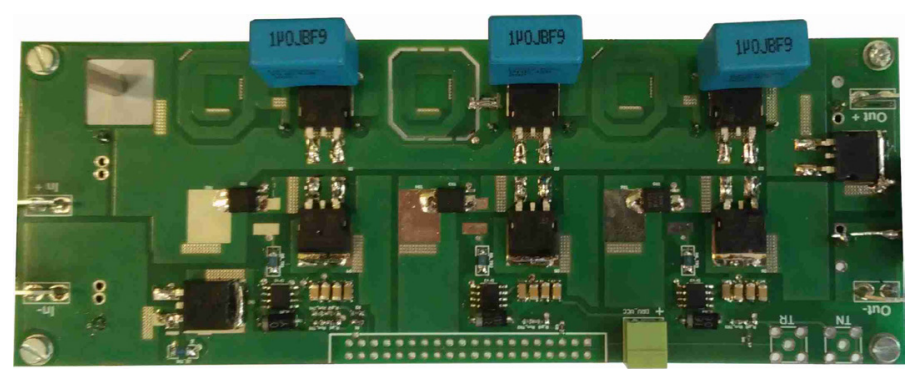

Fig. 5. Three-cell Cost-Effective SCVM

Table 2. Parameters of experimental setup of CESCVM

\begin{tabular}{cc}
\hline Items & Specification \\
\hline \hline Number of switching cells & 3 \\
Input voltage & $40 \mathrm{~V}$ \\
Low-side MOSFET & IRFS4229PbF \\
Discharging MOSFETs & $3 \times S I R 872$ \\
Switched capacitors Ck & $1.47 \mu \mathrm{F}$ \\
Resonant inductances Lk & $0.85 \mu \mathrm{H}$ \\
Diodes & STTH3006 \\
\hline
\end{tabular}

\section{Gate driver system}

In the CESCVM, the supply system for the gate drivers can still be designed as a bootstrap topology. It resembles that described by Waradzyn et al. (2017a) for the SCVM converter. In the CESCVM, there is a single low-side switch $\left(S_{\mathrm{d}}\right)$ and $n$ high-side (flying) switches $\left(S_{2,4,6}\right)$. The bootstrap capacitors of the high-side switches $\left(C_{\mathrm{b}}\right)$ are charged simultaneously through the low-side transistor and the low-side charging diodes. The supply system for the gate drivers in the CESCVM remains very simple and not expensive. In the experimental setup, IRS2181 gate drivers are used, but only one driver is used for the low-side transistor $S_{\mathrm{d}}$ control. The driver system can be further simplified.

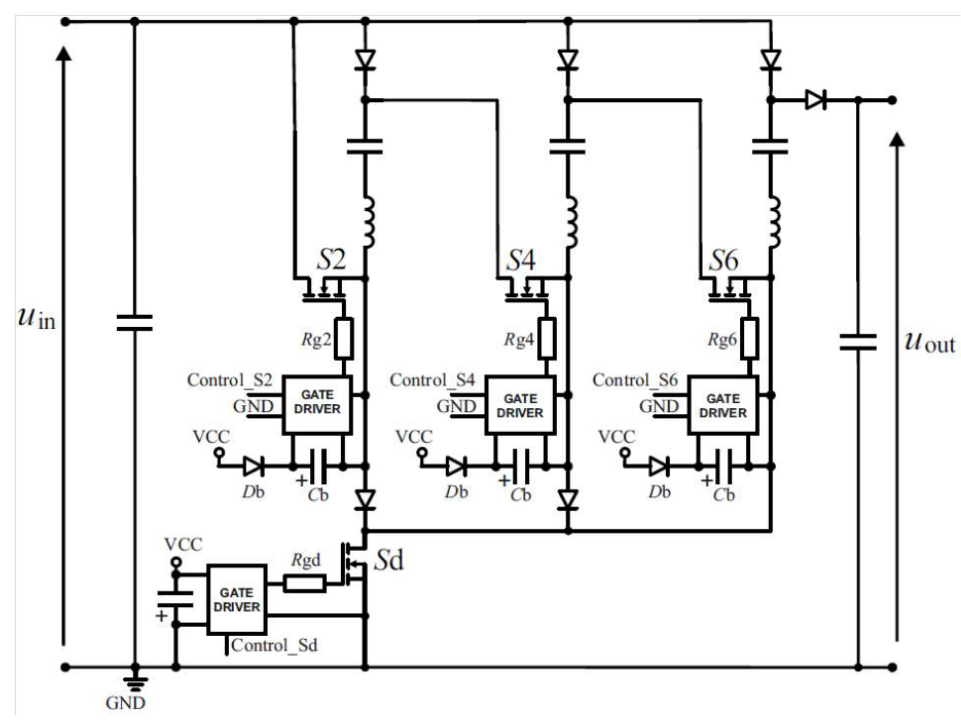

Fig. 6. Proposed gate driver system in CESCVM 


\section{Experimental results}

The operation of the CESCVM is similar to that of the SCVM described by Kawa et al. (2016), Mondzik et al. (2016) and Waradzyn et al. (2017a,b). In the CESCVM, there is only one low-side transistor $S_{\mathrm{d}}$. Figure 7 presents the experimental waveforms of the control signals for the transistors in the CESCVM, as well as the input current and voltage on a switched capacitor. The results confirm the feasibility of the converter, its operating idea, and the effectiveness of the gate driver system. Due to the impact of parasitic elements, the pulses discharging the switched capacitors are shorter than those that charge these capacitors.

Figure 8 presents the measurements of voltage stresses on the switches. From the results, it follows that the voltage on switch $S_{\mathrm{d}}$ is approximately equal to $3 U_{\text {in }}$, and the voltage on the series switch $S_{2}$ remains on the level of $U_{\text {in }}$.

The waveforms in Figure 9 confirm that the voltage stress on the low-side diode $D_{1 \mathrm{~d}}$, which is nearer the input, is larger than that on diode $D_{2 \mathrm{~d}}$ (Table 1).

Converter's efficiency $\eta$ and converter's output voltage $U_{\text {out }}$ are presented in Fig. 10, as a function of output power. The highest value of efficiency, equal to $92 \%$, occurs at $P_{\text {out }} \approx 100 \mathrm{~W}$. The efficiency is relatively low in comparison to a typical switch-mode boost converter. It could be improved by using a low-side transistor with low $R_{\mathrm{DS}(\mathrm{ON})}$ and diodes of low $V_{\mathrm{F}}$. Moreover, the comparison can be more beneficial in the case of a high-voltage-gain operation.

The output voltage is lower than the theoretical value of $160 \mathrm{~V}$, and the voltage gain is in the range from 3.91 at $20 \mathrm{~W}$ to 3.57 at $260 \mathrm{~W}$.

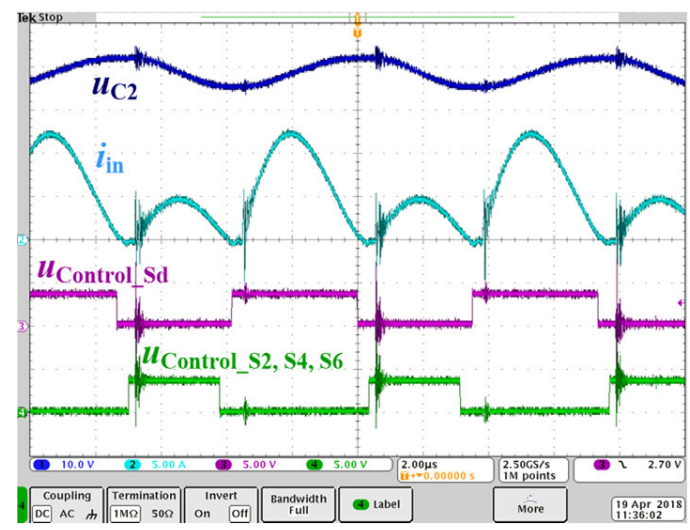

Fig. 7. Experimental results of CESCVM. Waveforms of voltage across switched capacitor C2 (1), input current $i_{\text {in }}$ (2) and gate control signals of transistors: charging transistor $S_{\mathrm{d}}(3)$, and discharging transistors $S_{2}, S_{4}, S_{6}(4) . U_{\text {in }}=40 \mathrm{~V}, P_{\text {out }} \approx 200 \mathrm{~W}$, dead-time $=350 \mathrm{~ns}$

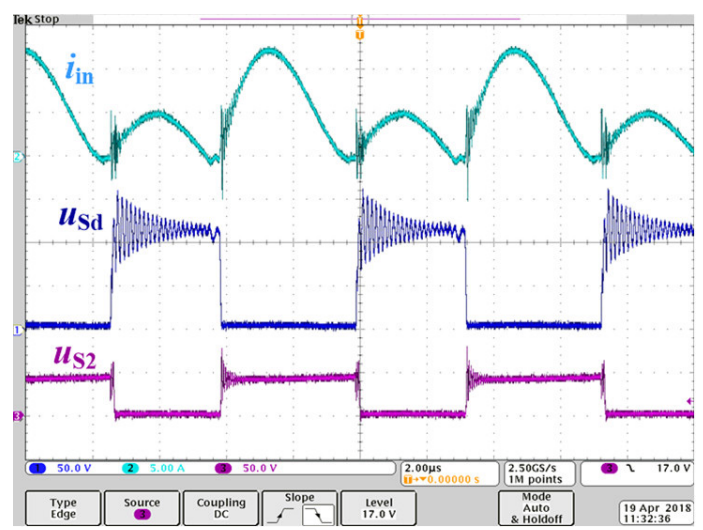

Fig. 8. Experimental results of CESCVM. Waveforms of input current $i_{\text {in }}$ (2), voltage across charging transistor $S_{\mathrm{d}}(1)$, and voltage across discharging transistor $S_{2}(3) . U_{\text {in }}=40 \mathrm{~V}, P_{\text {out }} \approx 200 \mathrm{~W}$ 


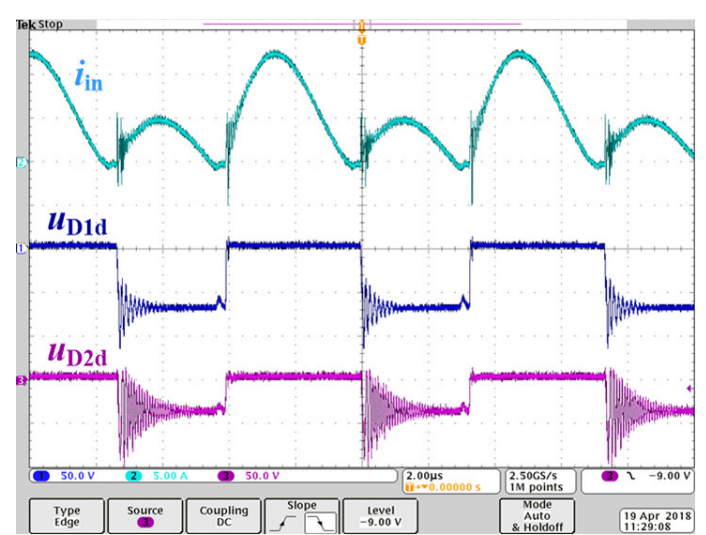

Fig. 9. Experimental results of CESCVM. Waveforms of input current (2), voltage across diode $D_{1 \mathrm{~d}}$ (1) and voltage across diode $D_{2 \mathrm{~d}}(3) . U_{\mathrm{in}}=40 \mathrm{~V}$, $P_{\text {out }} \approx 200 \mathrm{~W}$

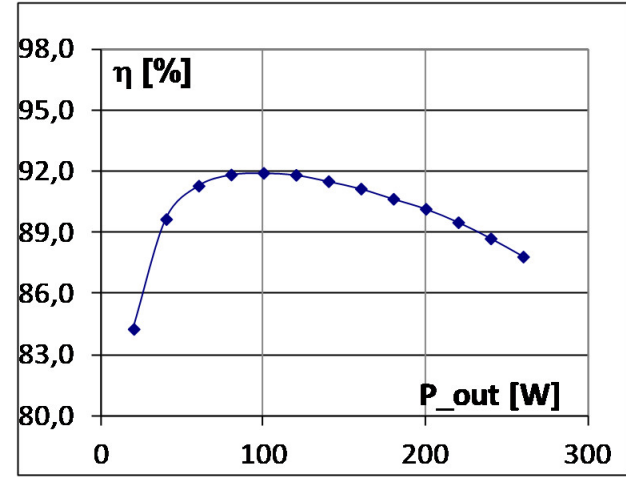

b)

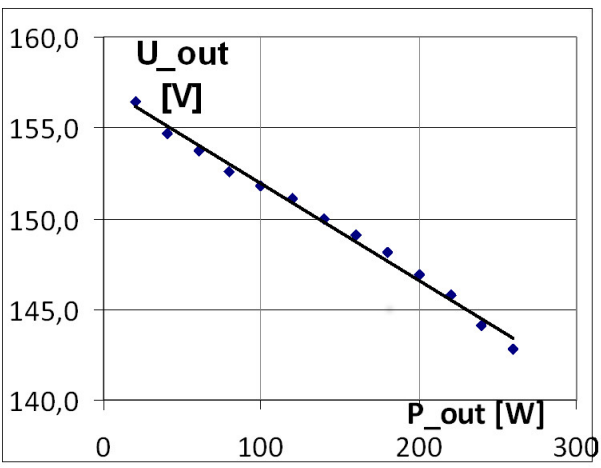

Fig. 10. Experimental results of CESCVM. Converter's efficiency $\eta$ (a) and converter's output voltage $U_{\text {out }}$ (b) vs. $P_{\text {out }} \cdot U_{\text {in }}=40 \mathrm{~V}$ and $f_{\mathrm{s}}=136.6 \mathrm{kHz}$

The IR image presented in Fig. 11 confirms that the vast majority of losses is generated in transistor $S_{\mathrm{d}}$; thus, the efficiency can be further improved by selecting a switch $S_{\mathrm{d}}$ of very low $R_{\mathrm{DS}(\mathrm{ON})}$.

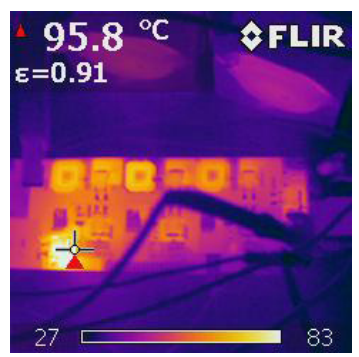

Fig. 11. Steady state operation at $250 \mathrm{~W}$ of output power. Hot spot located on transistor $S_{\mathrm{d}}$.

\section{Conclusions}

The results of the investigation of a cost-effective switched-capacitor voltage multiplier (CESCVM) make it possible to draw the following conclusions:

- $\quad$ The concept of the CESCVM is feasible,

- $\quad$ The CESCVM was tested in the setup with air-based resonant chokes. This is a significant benefit in comparison to a switch-mode boost converter where a large ferrite choke is used.

- $\quad$ The design with replacing $n$ low-side transistors with a single transistor and $n-1$ diodes is not complicated. 
This solution reduces the cost of the elements and saves space on the PCB, owing to a lower number of switches and gate driver circuits.

- The CESCVM can operate using a simple and not expensive gate driver system with a supply of high-side switches based on bootstrap circuits.

- The voltage stresses of the additional elements in the CESCVM are not equal. The voltage on the transistor is the same as that on the device nearest to the output in the basic SCVM. The diodes closer to the input side experience higher voltage stresses than those that are more distant. This is contrary to the voltage stresses in a basic SCVM, in which the low-side transistors nearer the input are exposed to lower voltages.

- The analysed CESCVM operates with relatively low efficiency in comparison to a typical switch-mode boost converter. However, the comparison can be more beneficial when high-voltage-gain operation is concerned.

- To improve the efficiency of the SESCVM, a low-side transistor with low $R_{\mathrm{DS}(\mathrm{ON})}$ and diodes of low $V_{\mathrm{F}}$ are required. In the analysed setup, a $42 \mathrm{~m} \Omega$ MOSFET was used.

- The CESCVM can only operate in its basic switching strategy (TS), unlike the SCVM in basic topology.

- In most cases, the efficiency of the CESCVM is lower than that of the SCVM. More significant benefits of the application of the cost-effective multiplier are supposed in the systems where switching losses in the transistors represent an important part of total losses (low-power, high-frequency, high voltage systems).

\section{References}

Alam, M. K. and Khan, F. H. (2014). Efficiency Characterization and Impedance Modeling of a Multilevel Switched Capacitor Converter Using Pulse Dropping Switching Scheme. IEEE Transactions on Power Electronics, 29(6), pp. 3145-3158.

Alijani, A., Adabi, J. and Rezanejad, M. (2016). A Bipolar High-Voltage Pulsed-Power Supply Based on Capacitor-Switch Voltage Multiplier. IEEE Transactions on Plasma Science, 44(11), pp. 2880-2885.

Ben-Yaakov, S. (2012). On the Influence of Switch Resistances on Switched-Capacitor Converter Losses. IEEE Transactions on Industrial Electronics, 59(1), pp. 638-640.

Cao D. and Peng F. Z. (2010). A family of zero current switching switched-capacitor dc-dc converters. In: Proceedings of the 25th Annual IEEE Applied Power Electronics Conference and Exposition (APEC), Palm Springs, CA, 21-25 February 2010, IEEE, pp. 1365-1372, doi: 10.1109/ APEC.2010.5433407, [INSPEC Accession Number: 11204556].

Cervera, A., Evzelman, M., Peretz, M. M. and BenYaakov, S. (2015). A High Efficiency Resonant Switched Capacitor Converter with Continuous Conversion Ratio. IEEE Transactions on Power Electronics, 30(3), pp. 1373-1382.

Cheung, C.-K., Tan, S.-C., Tse, C. K. and Ioinovici, A. (2013). On Energy Efficiency of SwitchedCapacitor Converters. IEEE Transactions on Power Electronics, 28(2), pp. 862-876.
Evzelman, M. and Ben-Yaakov, S. (2013). AverageCurrent-Based Conduction Losses Model of Switched Capacitor Converters. IEEE Transactions on Power Electronics, 28(7), pp. 3341-3352.

loinovici, A. (2001). Switched-Capacitor Power Electronics Circuits. IEEE Circuits and Systems Magazine, 1(3), pp. 37-42.

Kawa, A. H. and Stala, R. (2016). A Multilevel Switched Capacitor DC-DC Converter. An Analysis of Resonant Operation Conditions. Power Electronics and Drives, 1(2), pp. 35-53.

Kawa, A., Stala, R., Mondzik, A., Pirog, S. and Penczek, A. (2016). High Power Thyristor-Based DC-DC Switched-Capacitor Voltage Multipliers: Basic Concept and Novel Derived Topology with a Reduced Number of Switches. IEEE Transactions on Power Electronics, 31(10), pp. 6797-6813.

Lei, Y. and Pilawa-Podgurski, R. C. N. (2015). A General Method for Analyzing Resonant and Soft-Charging Operation of Switched-Capacitor Converters. IEEE Transactions on Power Electronics, 30(10), pp. 5650-5664.

Mak, O.-C., Wong, Y.-C. and loinovici, A. (1995). Step-up DC Power Supply Based on a SwitchedCapacitor Circuit. IEEE Transactions on Industrial Electronics, 42(1), pp. 90-97.

Mondzik, A., Waradzyn, Z., Stala, R. and Penczek, A. (2016). High efficiency switched capacitor voltage doubler with planar core-based resonant choke. In: CPE-e 2016, 10th International Conference on Compatibility, Power Electronics and Power 
Engineering, Bydgoszcz, Poland, 29 June - 01 July 2016, IEEE, cop, pp. 402-409.

Redondo, L. (2010). A DC Voltage-Multiplier Circuit Working as a High-Voltage Pulse Generator. IEEE Transactions on Plasma Science, 38(10), pp. 2725-2729.

Sakamoto, T., Nami, A., Akiyama, M. and Akiyama, H. (2012). A Repetitive Solid State Marx-Type Pulsed Power Generator Using Multistage SwitchCapacitor Cells. IEEE Transactions on Plasma Science, 40(10), pp. 2316-2321.

Waradzyn, Z., Stala, R., Mondzik, A., Penczek, A., Skała, A. and Pirog, S. (2017a). Efficiency Analysis of MOSFET-Based Air-Choke Resonant DC-DC Step-Up Switched-Capacitor Voltage Multipliers. IEEE Transactions on Industrial Electronics, 64(11), pp. 8728-8738. doi: 10.1109/ TIE.2017.2698368
Waradzyn, Z., Stala, R., Mondzik, A. and Pirog, S. (2017b). Switched capacitor-based power electronic converter - optimization of high frequency resonant circuit components. In: J. Kabziński, ed., Advanced Control of Electrical Drives and Power Electronic Converters, ser. Studies in Systems, Decision and Control, Vol. 75, Switzerland: Springer International Publishing AG, pp. 361-378.

Ye, Y., Cheng, K. W. E., Liu, J. and Xu, C. (2014). A Family of Dual-Phase-Combined Zero-Current Switching Switched-Capacitor Converters. IEEE Transactions on Power Electronics, 29(9), pp. 4209-4218.

Zajac, L., Malinowski, M., Styński, S. and Jasinski, M. (2017). Performance Study of a New High Instantaneous Power Impulse Converter with Switched Capacitor Unit. Power Electronics and Drives, 2(1), pp. 5-17. 